\title{
ORÇAMENTO
}

\section{Técnica Fiscal Colombiana}

\author{
Antônio C. CORTÉs
}

\begin{abstract}
C OMPREENDE o presente trabalho um estudo da técnica fiscal colombiana, seus reflexos sôbre o orçamento nacional, e uma análise de cada uma de suas fases.
\end{abstract}

No processo de preparação técnica do orçamento nacional, acabcu-se por adotar, na Colômbia, em 1950, como lei do país, o projeto elaborado por uma comissão de especialistas em finanças, que lograram cristalizar, mediante normas simples, teorias complexas sôbre a matéria, consultando, ao mesmo tempo, a finalidade econômica, a funcional e a administrativa. Assim, o orçamento colombiano revela: (1) Uma orientação econômica, ao classificar as despesas gerais em Despesas de Consumo, Despesas de Transferência, Despesas de Capital e Dívidas; (2) Uma orientação funcional, ao grupar as mesmas despesas em Despesas de Administração, de Justiça, de Defesa Nacional, de Ordem Interna, de Educação e Cultura, de Saúde Pública, etc. detalhando as dotações em vinte grupos funcionais diferentes, que correspondem às atividades governamentais durante o exercício; e (3) Uma crientação administrativa, que discrimina o montante das verbas, devidamente classificadas, destinadas a cada Ministério e a cada órgão do Govêrno.

Convém também advertir que essa lei orçamentária, sua execução e contrôle, tem como norma inviolável a exigência do equilíbrio rigorcso e real entre - Orçamento da Receita e o Orçamento da Despesa.

$\mathrm{Na}$ Colômbia, o exercício fiscal começa no dia $1^{\circ}$ de janeiro e termina a 31 de dezembro de cada ano. Rege-o o princípio da unidade orçamentária. Não há destinações especiais de rendas. Com o produto total da receita formase um acervo comum com o qual se efetuam tôdas as despesas autorizadas. $\mathrm{O}$ orçamento nacional ainda não abrange o mcrvimento anual de receita e despesas de numerosos estabelecimentos públicos descentralizados, que administram, com fundos nacionais, fora do orçamento, serviços de crédito agrícola, pecuário, de mineraçãc, de transportes, de construção de moradias, de exploração de petróleo e derivados, cujo volume global, em cada ano, se aproxima muito do montante do orçamento nacional.

Está êste dividido em três partes. A primeira, denominada Orçamento de Rendas e Receita, contém a relação das receitas cuia arrecadação se prevê ou de que se espera dispor durante o ano fiscal. A segunda, denominada Orçamento da Despesa, contém a relação detalhada das dotações que se autorizam para o mesmo período. A terceira, denominada Disposições Gerais, contém 
aquelas normas que se julguem oportunas para a ccrreta execução do respectivo orçamento.

O Orçamento de Rendas está composto de três grandes seções:

1. ${ }^{\text {) }}$ Estimativa das Rendas, que se forma com a arrecadação prevista para as receitas oriundas de impostos, taxas e quaisquer rendas contratuais ou ocasionais, autorizadas por leis anteriores;

2. ${ }^{\text {) }) ~ E s t i m a t i v a ~ d o s ~ R e c u r s o s ~ d o ~ B a l a n c ̧ o ~ d o ~ T e s o u r o ~ q u e ~ c o n t e ́ m ~ o ~}$ montante do superavit fiscal com que se espera liquidar os exercícios anteriores;

3. a) Estimativa dos Recursos de Crédito, que ccntém ùnicamente a relação dos empréstimos a longo prazo já autorizados e aos quais se espera recorrer.

As rendas abrangem três classes, segundo a sua natureza:

1) Rendas tributárias, que compreendem o produto periódico proveniente de impastos diretos, indiretos, taxas e multas;

2) Rendas Contratuais, que incluem as provenientes de atividades de natureza civil, comercial ou econômica que realiza o Estado e do valor das concessões, bens ou serviços, cedidos ou prestados, a particulares; e

3) Rendas ocasionais, que reunem as oriundas da tributação ou dos contratos que, acidentalmente, se incorporem ao crçamento e não constituam recursos periódicos.

O Orçamento das Despesas tem como base o da Receita, não pcidendo nunca o total do primeiro exceder o do segundo, devendo manter-se entre os dois o mais estrito equilíbrio.

As dotações destinadas às despesas abrangem também três classes:

1. ${ }^{\text {) }) ~ D e s p e s a s ~ O r d i n a ́ r i a s ; ~}$

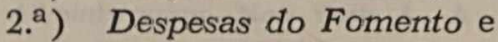

3. ${ }^{\text {) }) ~ D e s p e s a s ~ E x t r a o r d i n a ́ r i a s . ~}$

Qualificam-se de Despesas Ordinárias as que se tornam necessárias para o funcionamento normal e contínuo da administração pública, para o pagamento das obrigações contratuais e para o atendimento de créditos judicialmente reconhecidos. Estas despesas nãc podem ser diminuídas pelo Congresso ao estudar a proposta orçamentária. As Despesas Ordinárias compreendem:

a) Presidência da República;

b) Ministérios e Departamentos Administrativos;

c) Administração de Justiça;

d) Exército, Marinha e Aviação;

e) Polícia Nacional;

f) Educação Primária, Secundária e Universidade Nacional;

§) Higiene e Previdência Social;

h) Correios e Teleccmunicações;

i) Contrôle dos Bancos, das Sociedades Anônimas e das Cooperativas;

j) Arrecadação das Rendas;

k) Fiscalização da Administração Pública;

1) Serviço de Dívida Pública e as demais obrigações contratuais; 
m) Créditos judicialmente reconhecidos;

n) Subvenções às Caixas de Previdência Social de Empregados e Operários nacicnais e Fôrças Armadas; e

o) Despesas do Parlamento.

Qualificam-se de Despesas de Fomento as que se impõem para o desenvolvimento político, econômico, cultural e social do País e as que, sem corresponder a serviços essenciais do Govêrnc; são necessárias ao seu bom funcionamento.

Qualificam-se de Despesas Extraordinárias as destinadas a atender a despesas decorrentes da perturbação da ordem pública interna, guerra internacional ou calamidade pública.

\section{ELABORAÇÃO DO ORÇAMENTO}

A Estimativa das rendas tem por base o montante da arrecadação de cada grupo durante o ano fiscal imediatamente anterior, sem levar em consideração o custo administrativo da arrecadação. O Govêrno só pode aumentar até $10 \%$ a estimativa de cada grupo das rendas perićdicas, ou diminuí-1o até $30 \%$ de acôrdo com as perspectivas econômicas e fiscais que se antecipem para o respectivo ano fiscal.

Se o Govêrno julgar necessário propor novas fontes de receita, deve elaborar um projeto em separado e complementar, a que acrescentará a estimaiva dessas novas rendas, apresentando, outrossim, as despesas que devam ser custeadas com tais recursos financeiros.

$\mathrm{Na}$ estimativa da receita adota-se o princípio da universalidade, cumprindo incluir no referido cálculo tôdas as receitas provenientes de bens, serviços $\mathrm{cu}$ atividades dos órgãos nacionais, segundo seu rendimento bruto.

No Orçamento đas Despesas, não se pode incluir nenhuma soma que não corresponde ou a uma despesa decretada por lei anterior ou a um débito reconhecido. Isto é, crédito de terceiro devidamente reconhecido se os gastos decretados por leis anteriores excederem o montante das rendas e receitas financeiras, o Govêrno deixará de solicitar créditos orçamentários para as despesas menos urgentes, diminuindo também, tantc quanto possível, as somas ou percentagens ordenadas em leis anteriores.

O montante das dotações que se devem incluir no orçamento é fíxado pelo Presidente da República, assistido pelo Ministro da Fazenda, cumprindolhes, todavia, levar em conta o montante das contas e dos recursos do Balanço do Tesouro. Para fixar a importância dos créditos que deverão ser utilizados no ano fiscal em questão, pondera-se, além dos planos e programas legalmente aprovado's, a capacidade econômica do país.

Objetivamente, o Orçamento da Despesa prepara-se da seguinte forma: 1) Na primeira quinzena de março de cada ano, baseado nos dados que o Ministro da Fazenda apresentar sôbre a estimativa das rendas e dos recursos do Tesouro, o Presidente da República fixa o montante das Despesas Ordinárias, 
de Fomento e Extraordinárias, que convém sejam incluídas no Orçamento, e delineia a política orçamentária do Govêrno para o ano seguinte, destinando a cada Ministério e Departamento Administrativo uma percentagem dos gastos totais e mantendo, tanto quanto possível, uma eqüitativa distribuição dos dinheiros públicos entre as diversas regiões do país. Feito isto, o Presidente, antes de 15 de abril, comunica, por intermédio do Ministro da Fazenda, as suas decisões aos Ministros e Chefes de Departamentos Administrativos.

Cada Ministro e Chefe de Departamento Administrativo envia, antes de 10 de maio de cada ano, ao Diretor do Orçamento, dentro da percentagem fixada pelo Presidente, os seus pedidos de verbas, que devem ser consignadas na Proposta orçamentária. Se o Chefe de algum dêsses órgãos achar que a verba, que the foi arbitrada, é insuficiente para as suas atividades durante o ano respectivo, comunica-o ao Presidente da República expondo as suas razões. O Presidente notifica da sua decisão ao Ministro da Fazenda.

Na preparação das prcpostas os Ministros e Chefes de Departamento devem atender, em primeiro lugar, ao necessário para a prestação dos serviços gerais da Adminıstração Pública, ao serviço da Dívida Pública e às obrigações contratuais ou de natureza judicial, antes de incluir outros serviços ou projetos que possam ser eliminadcs ou reduzidos sem prejuízo da boa marcha da Administração.

Nas propostas devem constar os seguintes dados: a) a Divisão ou Seção a que se atribuem os créditos; b) a lei que autoriza a despesa ou Sentença Judiciária que a determina; c) o fim a que se destina cada verba solicitada; d) o montante apropriado para os mesmos gastos no ano em curso; e) o montante das verbas cuja inclusão se solicita na Proposta Orçamentária; f) exposiçäo dos motıvos do aumento ou diminuçâo das verbas que se pleiteiam ou as razões das necessidades ou conveniências quando se trata de novas despesas.

O montante total das propostas para as Despesas Ordinátias, de Fomento e Extraordinárias de cada Ministério ou Departamento Administrativo não poderá exceder o total estipulado pelo Presidente da República para cada órgão.

Os pedidos de inclusão de verbas na Proposta Orçamentária devem obedecer a certas normas: a) As verbas para despesas fixas ou periódicas devem ser suficientes no seu montante para a finalidade a que se destinam: as apropriações para vencimentos e salários justificam-se com o envio de relações nominais com os respectivos vencimentos; b) As verbas para despesas estimadas ou de montante variável devem ser iguais ao que tiver sido consignado para o ano em curso, salvo se se explicarem satisfatòriamente os motivos do seu aumento ou diminuição; c) As verbas para o Serviço da Dívida Pública devem corresponder exatamente ao montante do valor dos serviços dos empréstimos, segundo os respectives contratos; d) As verbas para prosseguimento de obras públicas em execução ou destinadas ao desenvolvimento de campanhas planificadas, devem ccrresponder aos montantes previstos pelos respectivos orçamentos de construção cu desenvolvimento para cada ano fiscal: e) 
Quando se estimam as verbas para obras públicas que tenham de empreenderse, cumpre correspondam exatamente às previstas para o ano no respectıvo plano ou programa; f) Os montantes para obras públicas em execução devem ser propustos de forma discriminada pelo respectivo Ministério ou Departamento Administrativo, destinándo-se uma dotação global para a aquisição de materiais, maquinaria e equipamento e outra para despesas de administração e salários; g) Para despesas imprevistas inclui-se no capítulo Despesas várias de cada Ministério ou Departamento uma verba que não pode exceder de $2 \%$ por mil do montante total dos créditos consignados a cada subdivisão; h) As verbas apresentam-se classificadas em duas colunas: uma, para Despesas Ordinárias e, outra, para as Despesas de Fomento. As Despesas Extraordinárias vão em último lugar.

A direção do Orçamento faz um estudo cuidadoso das propostas dos Ministérios e suas dependências e, quando estas não se ajustam às ncrmas legais, formula as observações que o caso requer, dando conhecimento ao Ministério ou Departamento respectivo antes de 15 de junho, para que sejam corrigidas até 25 do mesmo mês. Caso se vença êsse prazo sem se ter apresentado a solicitação de créditos por parte de alguma das repartições, incluir-se-ão no Orçamento as verbas determinadas pelo Presidente da República e o Ministro da Fazenda.

As verbas solicitadas e aprovadas e as que forem fixadas pelo Presidente são as únicas que integram a Proposta do Orçamento de Custeio. Êste dividese em tantas Seções quantos sejam os Ministétios e os Departamentos Administrativos. A estimativa das despesas de cada uma destas Seções desdobrase em capítulos e artigos. Os capítulos representam as diferentes unidades da organizaçãc, e os artigos, os fins ou objetos individuais das despesas.

Assim elabcrada, a Proposta Orçamentária deve evidenciar que o montante total das Despesas está em equilíbrio com o Orçamento de Rendas e Receita.

\section{ESTUDO DA PROPOSTA ORÇAMENTÁRIA PELO CONGRESSO}

O Govêrno submete a Proposta Orçamentária à consideração do Congresso Nacional por intermédio do Ministro da Fazenda, dentro dos primeiros 10 dias das sessões ordinárias de julho. Apresenta-se a Proposta à Câmara dos Deputados em forma comparativa, acompanha de uma Mensagem. O Orçamento de Rendas e Receita é acompanhado das seguintes infcrmações: $\left.1^{\circ}\right)$ Disposição legal em que se baseia a inclusão de cada uma das rendas ou recursos: $\left.2 .^{\circ}\right)$ Nome com que se distingue cada renda ou recurso; $3 .^{\circ}$ ) Arrecadação de cada renda no ano anterior; $4^{\circ}$ ) Estimativa com que cada renda figura no orçamento vigente; $5 .^{\circ}$ ) Arrecadação de cada renda até o mês de maio do exercício vigente; $6 .^{\circ}$ ) Estimativa de cada renda para o ano a que se vai aplicar o Orçamento; $\left.7 .^{\circ}\right)$ Motivos em que se baseia o aumento ou a diminuição de cada renda, relativamente à arrecadação do ano anterior.

O Orçamento de custeio é acompanhado, por sua vez, dos seguintes requisitos: $\left.10^{\circ}\right)$ Lei ou sentença judiciária em que se baseia a apropriação de cada 
verba; $\left.2 .^{\circ}\right)$ Importância gasta e empenhada por conta de cada artigo durante o ano precedente, de acôrdo com informações da Contadoria Geral da República; $3^{\circ}$ ) Importância votada para o mesmo artigo na lei crçamentária vigente; $4 .^{\circ}$ ) Importância proposta para o mesmo artigo; $5 .^{\circ}$ ) Aumento ou diminuição resultante do apropriado para o ano em curso; $6 .^{\circ}$ ) Explicação de tais aumentos ou diminuições e dos novos gastos que apareçam na Proposta; $7 .^{\circ}$ ) Situação do Tesouro Nacional em 31 de maic do ano em curso, segundo informações do Contador Geral;.$^{\circ}$ ) Tabelas nominativas $\epsilon$ de remuneração que justifiquem as dotaçóes inscritas para vencimentos e salários; 9.') Qualquer outra informação que o Govêrno entenda necessária para explicar e justificar o seu prçgrama orçamentário.

Juntamente com a Proposta Orçamentária, o Presidente envia ao Congresso uma Mensagem na qual expõe a política orçamentária para o respectivo ano financeiro.

Recebida a Proposta pela Câmara, passa ela à Comissão especializada, que é a de Constituição, a qual, por sua vez, a transmite a um dos seus membros, para que a estude sob os seus aspectos legais e proponha as retificações necessárias, seguindo-se os trâmites legislativos ordinários.

Se a Propcsta contiver falhas do ponto de vista legal, é devolvida ao Ministro da Fazenda, que as deve corrigir dentro de oito dias. Se a Comissão não se pronunciar, no prazo de dez dias do recebimento da Proposta segue ela o seu curso normal.

Após ter sido estudada pełe Câmara, passa a Proposta ao Senado, cnde a Comissão respectiva a analisa e apresenta ao Plenário sua decisão.

Nem a Câmara nem o Senado pode apropriar verbas que não tenham sido propostas à Comissão correspondente, nem modificar a Propesta noutro sentido. Só o Ministro da Fazenda pode solicitar, em nome do Govêrno, a criação de novas rendas cu recursos; a modificação das alíquotas das rendas; a modificação dos montantes de Despesas incluídos pelo Govêrno na Proposta Orçamentária; o estudo de novas verbas e a autorização para contrair empréstimos.

Nem o Govêrno nem o Congresso pode propor aumento das verbas solicitadas, nem a inclusão de novos gastos, se com êles se altera o equilíbrio entre o Orçamento das Despesas e o de Rendas. O Congresso pode eliminar ou reduzir qualquer crédito de despesa proposto pelo Guvêrno e substituí-lo por outro ou destiná-lo a aumentar os já existentes na Proposta, mas não pode diminuir os destinados a Despesas Ordinárias. Os créditos votados em leis aprovadas pelc Congresso durante o estudo das Propostas Orçamentárias só podem ser incluídos na mesma com a aprovação do Ministro da Fazenda e respeitadas as normas gerais sôbre a elaboração do Orçamento.

Nas Dispos:ções Gerais da terceira parte do Orçamento só se incluem aquelas normas relacionadas com as Rendas e as Despesas que tenham de servir para a execução do Orçamento, e vigorará ùnicamente durante o ano financeiro para o qual se destinam. Nessas disposições não se podem criar novos impostos nem abolir os existentes, nem tampouco derrogar ou modificar leis vigentes, nem decretar novas despesas. 


\section{PRORROGAÇÃO DO ORÇAMENTO}

Se a Proposta crçamentária não fôr aprovada pelo Congresso antes da meia noite de 10 de dezembro, continuará vigente o orçamento do ano anterior e antes de 31 de dezembro o Govêrno expede o decreto respectivo de prorrogaçãc do Orçamento.

Para efeito de sua prorrogativa entende-se por Orçamento anterior: 1) o Orçamento de Rendas e Receita e Lei de Apropriações aprovado pelo Congresso e encerrado pelo Govêrno nc exercício anterior; 2) Os créditos adicionais ao mesmo Orçamento autorizados pelo Congresso, bem comc os adicionais aos impcstos que houverem sido votados; 3 ) Os créditos adicionais administrativos abertos pelo Govêrno, mas aprovados pelo Congresso; 4) Estornos efetuados pelo próprio Congresso.

Feita a Estimativa das Rendas, o Govêrno expede um decreto de reajuste de orçamento, eliminando as despesas que tenham sido autorizadas apenas para aquêle ano financeiro; as verbas destinadas a custear fins já alcançados e, em geral, tôdas aquelas que tenham sido apropriadas e gastas na quantia decretada. Se feitas as eliminações, as rendas não chegarem a cobrir as despesas, cumpre que o Govêrno reduza estas até obter o equilíbrio.

\section{SANÇÃO DO ORÇAMENTO}

Cabe ao Poder Executivo sancionar nas seguintes bases o orçamento aprovado pelo Congresso:

1. ${ }^{\text {) }}$ Toma-se como ponto de partida a Proposta apresentada pelo Govêrno ao Congresso;

2. $\left.{ }^{\mathrm{a}}\right)$ Acrescenta-se, reduz-se ou suprime-se o que tenha sido acrescentado, reduzido ou suprimido pelo Congresso;

3. ${ }^{\text {) }) ~ C o r r i g e m-s e ~ o s ~ e r r o s ~ a r i t m e ́ t i c o s ~ e m ~ q u e ~ s e ~ t e n h a ~ i n c o r r i d o ; ~}$

4. ${ }^{\text {) }}$ Na parte de Disposições Gerais, incluem-se as que foram aprovadas pelo Congressc;

5. ${ }^{\text {) }}$ O decreto com que fica o orçamento sancionado deverá ser baixado antes do $10^{\circ}$ de janeiro;

6. ${ }^{\mathrm{a}}$ ) Como anexo ao Decreto sancionador, inserem-se especificamente as apropriações para c respectivo ano financeiro.

\section{PROGRAMAÇÃo MENSAL DE DESPESAS}

Com o fim de manter o equilíbrio do orçamento durante a sua execução, - Ministro da Fazenda, assistido pelo Diretor do Orçamento, elabora, durante os dez últimos dias de cada mês, um programa de despesas que pcissam ser executadas pelo Estado, acompanhado da relação de verbas que também poderão ser movimentadas pelas diferentes repartições, conforme as ementas com que estejam inscritas e tendo em conta os pedidos que lhe façam essas mesmas repartições antes do dia 20 de cada mês. Pondera ainda a arrecadação das 
rendas durante os meses já decorridos, a viabilidade dos recursos de crédito que se tenham incluído no orçamento e as necessidades do equilíbrio orçamentário. Êsses programas de despesas e obrigações são submetidos à aprovação do Conselho de Ministros antes do mês ao qual se aplicam.

Nem os Ministros nem os Chefes de Departamento Administrativo podem celebrar contratos, cu contrair obrigações à conta de um crédito orçamentário sem que, antecipadamente, tenha sido aprovada a despesa respectiva na programação mensal. Os contratos que se celebram sem êste requisito não obrigam de maneira alguma o Estado.

A programação mensal de despesa tem duas seções: uma para as despesas pagáveis com a arrecadação das rendas e outra para as aprçpriações que se devam atender com recursos oriundos de empréstimos.

O montante dos programas estabelecidos para despesas da primeira seção durante os primeiros oito meses de cada exercício tem, como limite máximc; a duodécima parte correspondente às respectivas apropriações. Do mês de setembro em diante o montante total dos programas não pode exceder a arrecadação apurada das rendas, segundo notificação expedida pelo Contador.

As despesas pagáveis com recursos oriundos de empréstimos padem ser incluídas na respectiva seção, conforme os montantes necessários, e enquanto o permitam as disponibilidades de tais recursos.

No montante dos programas de despesas de cada mês deverá incluir-se, obrigatòriamente, a totalidade das despesas ordinárias, fixas ou periódicas: a cota parte correspondente às apropriações destinadas ao serviço da Dívida Pública e ao total dos vencimentos e salários que se devam pagar no respectivo mês, antes de se consignarem verbas para obras e campanhas planejadas e para despesas acidentais que possam adiar-se, se fôr necessário.

'Se em qualquer mês o Ministro da Fazenda achar provável que o total efetivo das entradas do ano venha a ser inferior ao total de despesas, cabe ao Govêrno tomar as medidas necessárias para a redução do programa de despesas, podendo adiar, com a aprovação do Conselho de Ministros, total ou parcialmente, as não indispensáveis. Quando isto sucede o Govêrno determina quais as apropriações para Despesas de Fomento ou Extraordinários que terão sua execução adiada, parcial ou totalmente. Se o Congresso estiver reunido nessa altura o Govêrno pode solicitar as modificações que entender aconselháveis.

\section{EXECUÇÃO DO ORÇAMENTO}

Compete ao Ministro da Fazenda determinar a arrecadação das rendas, não impedindo que as provenientes de certos serviços, tais ccmo os de correios, de energia elétrica, de administração de portos, etc. possam ser arrecadadas diretamente por funcionários de outros Ministérios, mas prescrevendo-lhes a obrigação de depositar diàriamente as importâncias arrecadadas na Tescuraria Geral da República.

O montante que se autoriza para cada artigo de despesa na Lei de Apropriações deve aplicar-se exclusivamente ao objeto e a finalidade especificados no texto respectivo. 
A movimentação das apropriações para despesas está a cargo dos respectivcs Ministros e Chefes de Departamentos.

\section{CONTRÔLE ADMINISTRATIVO DO ORÇAMENTO}

Compete ao Ministro da Fazenda a fiscalização administrativa das atividades orçamentárias em todos os ćrgãos do Govêrno, sem prejuízo do contrôle a cargo da Contadoria Geral da República.

Existe, subordinado ao Ministério da Fazenda, um departamento denominado Direção do Orçamento, cujo encargo consiste em elaborar, executar e fiscalizar, administrativamente, conforme a legislação orçamentária vigente, o Orçamento Nacional. O Diretor dêsse Departamento é nomeado pelo Presidente da República, com categoria igual à de Ministro, devendo ser especializado em contabilidade e legislação fiscal. As suas funções são:

1. ${ }^{\text {a }) ~ P r e p a r a r ~ a ~ P r o p o s t a ~ o r c ̧ a m e n t a ́ r i a ~ a n u a l ; ~}$

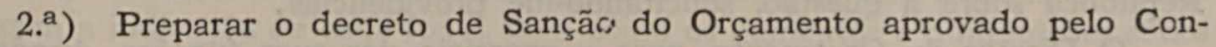
gresso ou o de Prorrogação do Orçamento anterior;

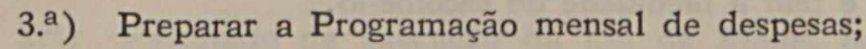

4. ${ }^{a}$ ) Preparar os projetos de créditos adicionais e de estornos de verbas que $c$ Govêrno julgue convenientes;

5. ${ }^{a}$ ) Preparar os projetos de créditos administrativos abertos pelo Govêrno e que devam submeter-se à aprovação do Congresso;

6. ${ }^{a}$ ) Fazer os estudos prévios para que o Presidente da República possa determinar o vclume total das apropriações e o das verbas globais para cada Ministério ou Departamento Administrativo;

7. ${ }^{a}$ ) Fiscalizar administrativamente a execução do Orçamento em todos os órgãos de Administração, mantendo um conhecimento detalhado de como se estão movimentando as respectivas verbas, criligindo dados a respeito dos empenhos e despesas; comparando o custo de serviços similares em diferentes órgãos e promovendo junto ao Ministro da Fazenda a adoção de medidas tendentes a obter econcmia no custo da Administração;

8. ${ }^{a}$ ) Promover a organização de Juntas Coordenadoras para unificar e simplificar as atividades da administração com pessoal especializado em cada ramo e cujos estudos sirvam de base aos projetos que devam ser submetidos à ccnsideração do Presidente da República;

9. a) Estudar o número de empregados e as classificações de despesas nas diferentes dependências do Govêrno;

$10^{\mathrm{a}}$ ) Estudar a execução orçamentária através dos balancetes e informações mensais e anuais que apresente o Contador Geral da República e manter informado de tudo o Ministro da Fazenda;

11 a) Colaborar $\mathrm{ccm}$ as Comissões do Congresso no estudo do Projeto de Orçamento;

12 ${ }^{\mathrm{a}}$ ) Estudar o funcionamento das entidades descentralizadas do Estado que atuam fora do sistema orçamentário nacional, sempre que o Govêrno determine; 
13 ${ }^{\text {a }}$ Estudar, pesquisar e planejar, sempre que o Govêrno o entenda, a reorganização e o funcionamento de qualquer órgão oficial;

14 a) Estudar os projetos de lei sôbre questões financeiras e orçamentárias que se submetam à consideração do Congresso;

15a ) Coligir estatísticas a respeito da situação econômica e financeira do País, que permitam ao Govêrno planejar a política orçamentária de cada anc;

16 ${ }^{\mathrm{a}}$ ) Realizar quaisquer trabalhos que o Govêrno the confie em conformidade com as suas atribuições.

As atividades de supervisão e contrôle administrativos da execução orçamentária não podem interferir na política de cada Ministério ou Departamento Administrativo, na mcrvimentação e aplicação das verbas de que disponham. Tcdavia, se o Ministro da Fazenda observar que se realizam despesas desnecessárias, excessivas ou supérfluas, pode notificar o Presidente da República sôbre a questão, solicitando-lhe providências.

O Diretor do Orçamento, para o exercício das suas funções, dispõe de pesscal especializado e tem a faculdade de escolhê-lo.

\section{CRÉDITOS ADICIONAIS}

Quando, durante a execução do orçamento, fôr indispensável aumentar o volume das apropriações para Despesas, ou para completar verbas insuficientes, ou para ampliar serviços já existentes, ou ainda para implantar novos que forem autorizados por lei, podem abrir-se, pelc. Congresso ou pelo Govêrno em conformidade com as normas legais, créditos adicionais.

Quando essa necessidade se apresentar, estando o Congresso em recesso, o Govêrno pcde abrir os créditos suplementares ou extraordinários com a aprovação do Conselho de Ministros e prévio assentimento do Conselho de Estado. Submete-se ao Congresso uma relação de tais créditos, juntamente ccm cópias autênticas dos documentos que os autorizaram, no primeiro mês de sessões ordinárias, a fim de que sejam ratificados e legalizados.

Os créditos adicionais, enquanto o Congresso está em recesso, não podem exceder em cada exercício $10 \%$, do montante total da Lei de Apropriação vigente, salvo se tratar de gastos ccasionados por perturbação da ordem pública no interior, guerra internacional ou calamidade pública.

Todo crédito adicional deve basear-se em algum dos seguintes fatos, devidamente comprovados pelo Contador: 1) Que o exercício fiscal imediatamente antericr tenha sido encerrado pela Contadoria com superavit e que dêle se possa dispor por não ter sido incluído no Orçamento vigente; 2) Que existam recursos ou operações de crédito legalmente autorizadas, ainda não incorporadas ao Orçamento vigente e que, portanto, pcssam servir de base à abertura do crédito; 3) Que exista saldo de crédito não utilizado e desnecessário durante todo o exercício em alguma verba da Lei de Apropriações, e que, na cpinião do Ministro ou Chefe de Departamento Administrativo interessado, possa ter outra aplicação; 4) Que no Balanço do Tesouro da Nação se tenha cancelado um crédito correspondente ao ano anterior, ou por ter desaparecido 
a obrigaçãc que o originou, ou por ter expirado o seu prazo de pagamento, o que pode servir como razão à abertura do crédito adicional, desde que não exista deficit no Balanço do Tesouro.

Nem o Congresso nem o Govêrno pode abrir créditos adicionais ao Orçamento sem que a lei ou o decreto respectivo estabeleçam de forma clara e precisa o recurso que pode servir de base a tal abertura.

\section{CONTA GERAL DO ORÇAMENTO E DO TESOURO}

De acôrdo com a Constituição Nacional cabe ac Contador Geral da República apresentar anualmente, durante os primeiros 10 dias da sessão ordinária, à Câmara de Representantes, a Conta Geral do Orçamento e do Tesouro.

A Conta deve consignar o seguinte:

1. ${ }^{\circ}$ Demonstração especializada da arrecadação das Rendas e Receitas com a indicação de cada fonte, bem como os aumentos e diminuições sôbre o estimado;

2..$^{\circ}$ Resultado da execução dả Lei de Meios, especificadamente, por Ministérios e Departamentos Administrativos, Capítulos e Artigcs, indicando o montante das adições, dos contracréditos, despesas comprovadas e das importâncias restantes;

3. ${ }^{\circ}$ Demonstração comparativa da Receita e das Despesas orçamentárias, em que se mostre a arrecadação global das rendas, dc's empréstimos, o montante das Despesas e reservas, do superavit ou do deficit;

4. $\left.{ }^{\circ}\right)$ Situação da Dívida Pública Nacional;

5..$^{\circ}$ Balanço da Nação com classificação do ativo e passivo, acompanhado de análises gerais e individualizadas das contas que o integram;

6. $\left.{ }^{\circ}\right)$ Relação detalhada das despesas pagas durante o exercício à conta de créditos do exercício anterior; Geral.

7. ${ }^{\circ}$ ) Recomendações que o Contador haja por bem fazer sôbre a Conta

Se, passados dois anos desde a data da prestação de contas, a Câmara não se pronunciar sôbre a mesma, entendem-se essas Contas aprovadas. 